\title{
Impactos do Câncer na Vida Escolar de Crianças e Adolescentes: a Importância da Classe Hospitalar
}

\author{
doi: https://doi.org/10.32635/2176-9745.RBC.2018v64n3.47 \\ Impacts of Cancer on the School Life of Children and Adolescents: the Importance of Hospital Class \\ Impactos del Cáncer en la Vida Escolar de Niños y Adolescentes: la Importancia de la Clase Hospitalaria
}

Vanessa de Magalhães Gonçalves Silva'; Senir Santos da Hora²

\section{INTRODUÇÃO}

A escolarização de crianças e adolescente em situaçóes de adoecimento por câncer se apresenta de forma desafiadora, uma vez que o tratamento oncológico impacta nas atividades habituais de escola e lazer desses que vivenciam o contato estreito com situaçôes de dor, mutilaçôes e efeitos colaterais que desencadeiam graves reaçôes físicas e emocionais.

Para auxiliar na inclusão escolar da criança e do adolescente que enfrentam tais condiçôes - prevenindo a reprovação e consequente evasão - a classe hospitalar tem sido importante, na medida em que busca oferecer assistência pedagógica aos que se encontram impedidos de frequentar o ambiente escolar formal por motivo de saúde.

Nesse sentido, busca-se compreender os impactos do adoecimento por câncer à vida escolar de crianças e adolescentes, considerando as possíveis sequelas do tratamento oncológico e os desafios do atendimento pedagógico hospitalar para inclusão escolar desses sujeitos.

\section{ADOECIMENTO POR CÂNCER E A VIDA ESCOLAR DE CRIANÇASE ADOLESCENTES}

O câncer é a segunda maior causa de hospitalização de crianças e adolescentes ${ }^{1}$. Estudos vão revelar que, no contexto da classe hospitalar brasileira, os problemas oncológicos correspondem a $12 \%$ dos casos, ficando atrás apenas da desnutrição, que representa $22 \%$, se igualando à pneumonia também com $12 \%{ }^{1}$.

Para além de ser uma doença grave que ameaça eminentemente à vida da criança, o tratamento do câncer é extremamente agressivo gerando efeitos colaterais físicos, psicológicos e sociais, imediatos e tardios, evanescentes ou perduráveis.
O tratamento do câncer se dá por meio do cumprimento de protocolos rigorosos que, na maioria dos casos, desencadeiam uma série de efeitos colaterais devastadores. Entre os principais efeitos do tratamento oncológico, pode-se mencionar a dor acentuada, cansaço excessivo, náuseas, vômitos, falta de apetite, diarreia, baixa imunidade, queda de cabelo, irritabilidade, intoxicaçóes, mucosites, abrupto emagrecimento ou inchaço, entre outros sintomas que restringem o paciente ao isolamento, quase que total em alguns casos. Por conseguinte, evidencia-se uma indicação médica para o afastamento imediato da criança da escola por um tempo indeterminado ${ }^{2}$.

Os impactos do adoecimento por câncer na vida escolar de crianças e adolescentes podem variar em razão das sucessivas e imprevisíveis internaçóes, dos abalos emocionais e socioeconômicos que a família precisa contornar, das possíveis limitaçóes físicas e cognitivas por conta da doença e do tratamento, entre outras questôes. No entanto, estudos ${ }^{2}$ evidenciam que a escolarização e a relaçáo entre pacientes e professores têm se apresentado como algo especialmente significativo para eles.

Em vista disso, o tratamento oncológico se constitui como um marco desafiador para a família e para a criança ou adolescente acometido desde o momento do diagnóstico. A criança que, outrora se via no ápice de sua performance e desenvolvimento físico, emocional e social, estreia um ciclo de imprevisíveis e contínuas hospitalizaçōes, exames e procedimentos dolorosos e invasivos.

A rotina das crianças e adolescentes com câncer é cercada de incertezas e instabilidade. Vivenciam a incomodidade da exibição do seu corpo, tendo suplantada, muitas vezes, a sua própria vontade. E o fato de que algumas delas ainda não possuam uma capacidade de compreenção plena do que se trata, o que vai depender da

${ }^{1}$ Instituto Nacional de Câncer José Alencar Gomes da Silva (INCA). Rio de Janeiro (RJ), Brasil. Orcid iD: https://orcid.org//0000-0001-8447-514X

2 INCA. Rio de Janeiro (RJ), Brasil. Orcid iD: https://orcid.org/0000-0002-0161-3701

Endereço para correspondência: Senir Santos da Hora. Travessa Durval Corrêa de Sá, 26 - Serra do Sambe. Rio Bonito (RJ), Brasil. CEP 24800-000. E-mail: senirsantos@hotmail.com. 
idade, não irá minimizar os efeitos psicológicos inerentes à passagem pelo ambiente hospitalar.

A falta de inclusão escolar para crianças e adolescentes submetidas a tratamentos de saúde, principalmente quando prolongados, como nos casos de doença oncológica, pode resultar em sentimento de inferioridade desencadeando uma série de prejuízos consideráveis ao seu desenvolvimento emocional e social.

A educação é fundamental para a formação de todo indivíduo, contribuindo para a construção da capacidade crítica e consolidação da cidadania. Nessa direçáo, a educação inclusiva pressupóe a garantia dos direitos humanos:

que conjuga igualdade e diferença como valores indissociáveis, e que avança em relação à ideia de equidade formal ao contextualizar as circunstâncias históricas da produção da exclusão dentro e fora da escola ${ }^{3}$.

\section{A CLASSE HOSPITALAR NO SERVIÇO DE ONCOLOGIA PEDIÁTRICA}

A classe hospitalar tem sido a estratégia de ação que integra sistemas de saúde e educação, buscando avalizar uma assistência pedagógica especializada aos educandos impossibilitados de frequentar a escola. Essa estratégia visa a garantir a continuidade da aprendizagem e a promover saúde integral, evitando a evasão escolar durante e depois do tratamento.

$\mathrm{O}$ atendimento pedagógico-educacional em ambiente hospitalar é uma modalidade da educação especial que garante a universalidade do direto à educação, que está previsto na Constituiçáo Federal de 1988, no Estatuto da Criança e do Adolescente (ECA), na Política Nacional de Educação Especial, no Conselho Nacional dos Direitos da Criança e do Adolescente (Conanda) e ainda na Lei de Diretrizes e bases da Educação (LDB) no. $9.394 / 96^{4-8}$. Esse atendimento se dá por meio de uma parceria na qual caberá ao hospital ofertar o espaço físico apropriado e, à Secretaria de Educação, disponibilizar o profissional devidamente habilitado.

O professor no contexto hospitalar é o profissional que permeia a relaçáo entre a criança e/ou adolescente e a escola de origem, enquanto estes estão hospitalizados ou em quimioterapia ambulatorial. O docente no contexto da classe hospitalar fará a aplicação dos conteúdos correspondentes ao nível de escolarização do aluno hospitalizado ou em quimioterapia ambulatorial. Dessa forma, a classe hospitalar trabalha em constante interação junto à equipe multiprofissional favorecendo a promoção da saúde por meio do desenvolvimento cognitivo aliado à reabilitação física, emocional e social.

A maneira como crianças e adolescentes lidam com as situaçóes e experiências adversas durante o tratamento vai depender do seu grau de amadurecimento cognitivo. Os reflexos da doença para a criança variam de acordo com a gravidade, sintomas apresentados, tratamento e evidência9.

Alguns estudos ${ }^{10,11}$ revelam que, entre os efeitos colaterais imediatos e tardios, as mudanças físicas geradas pelo tratamento do câncer são o principal motivo de constrangimento e dificuldade para a criança e o adolescente que desejam frequentar o ambiente escolar formal durante o tratamento. Embora o afastamento por recomendação médica geralmente se dê por motivo de debilidade física e vulnerabilidade imunológica, as transformaçóes na aparência são apontadas pelos pacientes como geradoras de curiosidades e preconceitos que suscitam estresse, medo e angústia.

Os fundamentos da atenção psicossocial à criança e ao adolescente com doenças crônicas devem atentar para a importância da socialização, das limitaçôes impostas, do desenvolvimento de indivíduos produtivos e autônomos, considerando o suprimento de necessidades reais e o respeito às limitações ${ }^{10}$.

Adoecer na infância interfere em um momento fundamental do desenvolvimento humano. A classe hospitalar é um importante instrumento que se propóe a preservar o vínculo da criança e do adolescente em tratamento com sua escola de origem para que estes possam dar continuidade ao desenvolvimento de seus processos de aprendizagens, garantindo um desenvolvimento intelectivo e emocional sadio, estimulando suas potencialidades e preservando suas perspetivas de construção do conhecimento e da vida.

A manutençáo do vínculo com a escola de origem e a aplicação dos conteúdos escolares pertinentes buscam assegurar a inclusão escolar dos pacientes mesmo durante o tratamento da doença. Esse tipo de ação educacional na perspectiva da educação inclusiva está prevista na Política Nacional de Educação ${ }^{3}$, que busca garantir educação para todos e se dirige a educandos que, por motivos distintos, encontram-se impedidos de frequentar as salas de aulas regulares.

Embora a classe hopitalar tenha um local disponibilizado pelo próprio hospital para sua realização, o atendimento pedagógico-educacional não tem um espaço físico determinado, pois o professor é desafiado a criar estratégias para atender cada aluno em sua especificidade e particularidade. Assim, a criatividade e a flexibilidade são notáveis caracteríscas desse tipo de ação docente que supera inúmeras limitaçôes para garantir que cada educando tenha o direito de continuidade dos processos de desenvolvimento e de aprendizagem como sujeitos ativos.

Bernat et al. ${ }^{12}$ destacam que estudos realizados pela equipe multidisciplinar do Instituto Nacional de Câncer José Alencar Gomes da Silva (INCA) apontam para necessidade de discutir os critérios para o afastamento 
dos pacientes em tratamento do ambiente escolar. A pesquisa demonstra que, na prática cotidiana da equipe, há uma extensa diversidade de critérios levando à conclusão de que cada caso deve ser considerado em sua particularidade. A equipe defende que o afastamento escolar desses sujeitos deva se dar apenas quando indubitavelmente necessário ${ }^{12}$.

Contudo, outros autores ${ }^{9-11}$ apontam que o ambiente escolar regular nem sempre se apresenta de maneira agradável para o paciente em tratamento e pós-tratamento, visto que o coloca diante de suas limitaçóes, sujeito a lidar com a curiosidade, preconceito e até mesmo sofrerem bullying. Nesse sentido, destaca-se a importância da aceitaçáo por parte da escola de origem diante da situação do aluno em tratamento oncológico ${ }^{11}$.

\section{CONCLUSÃO}

$\mathrm{O}$ aumento do número de pacientes infantojuvenis acometidos pelo câncer cresce de maneira alarmante, e, em termos epidemiológicos, consequentemente, esse dado sinaliza a necessidade de medidas que possibilitem a estruturação da modalidade educacional no ambiente hospitalar. Esse imprescindível recurso precisa estar ao alcance de todos que dele necessitarem, visto que as terapias antineoplásicas geram efeitos colaterais imediatos e tardios que acarretam prejuízos ao desenvolvimento global desses pacientes.

Não obstante, destaca-se a importante iniciativa por parte dos hospitais e dos órgãos de educação para implantação do serviço escolar hospitalar, viabilizando a escolarização de crianças e adolescentes que se encontram em tratamento e intermediando a reinserção à escola regular. A perspectiva de educação inclusiva deve nortear também essa proposta de ensino, desviando o foco das limitaçóes e dificuldades da doença e do ambiente hospitalar e se voltando para as infinitas e novas possibilidades que o aluno doente e a escola, dentro ou fora do hospital, podem revelar. Assim, cabe aos órgãos oficiais de educação prover os recursos humanos e materiais em quantidades adequadas e aos hospitais garantirem espaço físico e apoio multiprofissional estruturados para o suprimento dessa demanda.

\section{CONTRIBUIÇÕES}

Ambas as autoras contribuíram em todas as etapas do manuscrito.

\section{DECLARAÇÃO DE CONFLITO DE INTERESSES}

Nada a declarar.

\section{FONTES DE FINANCIAMENTO}

Não há.

\section{REFERÊNCIAS}

1. Fonseca ES. Classe hospitalar: ação sistemática na atenção às necessidades pedagógico-educacionais de crianças e adolescentes hospitalizados. Temas Desenvolv. 1999;8(44):32-7.

2. Instituto Nacional de Câncer José Alencar Gomes da Silva. Câncer da criança e adolescente no Brasil: dados dos registros de base populacional e de mortalidade. Rio de Janeiro: INCA; 2016.

3. Ministério da Educação (BR), Secretaria de Educação Especial. Política nacional de educação especial na perspectiva da educação inclusiva [Internet]. Brasília, DF: Ministério da Educação; 2008 [citado 2008 Nov 8]. [Documento elaborado pelo Grupo de Trabalho nomeado pela portaria n. 555/2007, prorrogada pela portaria n. 948/2007, entregue ao ministro da Educação em 7 de janeiro de 2008]. Disponível em: http://portal. mec.gov.br/arquivos/pdf/politicaeducespecial.pdf.

4. Oliveira J, organizador. Constituição. Constituição da República Federativa do Brasil: promulgada em 5 de outubro de 1988. 4 ed. São Paulo: Saraiva, 1990. [Série Legislação Brasileira].

5. Ministério da Saúde (BR). Estatuto da criança e do adolescente. 3 ed. Brasília: Ministério da Saúde; 2008. [Série E. Legislação de Saúde].

6. Ministério da Educação e do Desporto (BR), Secretaria de Educação Especial. Política Nacional de Educação Especial: livro 1 [Internet]. Brasília, DF: Ministério da Educação e do Desporto: 1994 [citado 2018 Out 9]. Disponível em: https://midia. atp.usp.br/plc/plc0604/impressos/plc0604_aula04_ AVA_Politica_1994.pdf.

7. Conselho Nacional dos Direitos da Criança e do Adolescente. Resoluçóes junho de 1993 a setembro de 2004. Brasília: Secretaria Especial dos Direitos Humanos, 2004. Disponível em: http://ens.sinase.sdh. gov.br/ens $2 /$ images/conteudo/Resoluca $\% C C \% 830 \% 20$ 1-99.pdf.

8. Presidência da República (BR). Lei n. 9394 de 20 de dezembro de 1996 [Internet]. [acesso 2018 Set 13]. Disponível em: https://www.planalto.gov.br/ccivil_03/ Leis/L9394.htm.

9. Hostert PCCP, Motta AB, Enumo SRF. Coping da hospitalização em crianças com câncer: a importância da classe hospitalar. Estud Psicol. 2015;32(4):627-39.

10. Moreira GMS. A criança com câncer vivenciando a reinserção escolar: estratégia de atuação do psicólogo [Dissertação]. Ribeirão Preto: Universidade de São Paulo; 2002. 
11. Paterlini ACCR, Boemer MR. A reinserção escolar na área da oncologia infantil- avanços \& perspectivas. Rev Eletr Enfe. 2008;10(4):1152-8.

12. Bernat ABR, Wepler BB, Oliveira ICM, Rabelo MA, Costa NG, Santos RM. Especificidades do sofrimento psíquico apresentado por crianças e adolescentes ao longo do tratamento onco-hematológico: Impasses e invençôes- Por que estudar é táo importante? In: Instituto Nacional de Câncer José Alencar Gomes da Silva. Cadernos de psicologia: sofrimento psíquico do paciente oncológico: o que há de específico? n. 2. Rio de Janeiro; INCA; 2014. p.101-08.

Recebido em 6/9/2018

Aprovado em 13/11/2018 